(RESEARCH ARTICLE)

\title{
Phytoremideation of ethylene glycol induced renal calculi in the vertebrate model Rattus norvigicus
}

\author{
Sutar Vishal Sambhaji and Kamble Nitin Anandrao* \\ Department of Zoology, Shivaji University, Kolhapur- 416 004, India.
}

Publication history: Received on 13 June 2019; revised on 24 June 2019; accepted on 28 June 2019

Article DOI: https://doi.org/10.30574/gscbps.2019.8.1.0104

\begin{abstract}
Multicellular organisms have special feature to concentrate and excrete nitrogenous wastes from the body. Normally kidneys in vertebrates have extensive role in the filtration and elimination function. Urinary calculi or stones are the most common cause for chronic / acute obstruction of urinary system. Pathologically urolithiasis (nephrolithiasis) relates with kidney stone disease. Understanding of the pathophysiology of nephrocytes with altered blood and urine constituents found to be thrust area of urolithiasis; therefore, present investigation has intended to focus on mechanism for development of calculus in kidney and phytoremideation against Ethylene glycol (EG) induced nephritic cells. With the intension vertebrate model rat have been used to understand pathogenesis and dose dependent recovery mechanism of two plant extract of Tribulus terrestris ( $\mathrm{Tt}$ ) and Amranthus cruentus (Ac). All animals were subjected to EG induction as a first part of experimental design. The recovery mechanism considering urine profile and histological observations were carried out with treatment of plant extracts. Observations in relations to doses compensation against EG were statically documented. Results of the different toxic concentration and exposure period were observed histologically and interpreted for comparative effects of plant extract (AC: TT) pertaining depleted percentage of crystal formation responsible for stone development. The overall mechanisms of phytoremideation were critically studied and interpreted in universally accepted vertebrate experimental model Rattus norvigicus.
\end{abstract}

Keywords: Urolithiasis; Ethylene glycol (EG); Phytoremideation; Urine profile; Histology; Rattus norvigicus

\section{Introduction}

The excretory system is responsible for the elimination of waste products. Historically Charka Samhita beautifully explained the medical background including anatomy, physiology and pathology of kidney with excretory mechanism. India is an ancient, historic and diverse country having huge knowledge of medicines in Ayurveda and folk medicines with all kind of remedial purposes. Urolithiasis is an ancient disease with worldwide distribution and reported most common, serious and life threatening disorder worldwide [1]. Biochemically high concentration of calcium carbonate in water and low nutrients diet were found major factors for the calcium dependent stone formation [2]. The amount of calcium oxalate, hydrogen, sodium, uric acid in the urine profile responsible for supersaturation and as initial step for the formation of kidney stone [3]. It has been documented that urolithiasis found to be a metabolic disease caused by a number of endogenous as well as exogenous factors which were associated with hereditary tendency towards stone formation in the interim mechanism of nephritic cells [4].

Most of the research relevant to kidney stone and crystals formation reported that biochemically calculus were made up of calcium oxalate salt [3]. Chemically stone contains calcium, magnesium, ammonium phosphate, uric acid, cystine in which almost 70-75 \% of urinary stone are calcium containing stone [5]. It has been documented that,

\footnotetext{
${ }^{*}$ Corresponding author

E-mail address:drknitinkumar@yahoo.in
} 
composition of urinary stone includes two phases i.e. crystaled and non crystaled or also called as organic matrix of nephrocytes [6]. [7] Reported that, metabolism pertaining to formation of higher concentration of calcium stimulates calcium oxalate crystal development in the tubular epithelial cells of mammalian model as rat. [8], provided information about metabolic assessment of recurrent development of renal calcium oxalate stone in vertebrate animals. According to clinical physiology urolithiasis or nephrolithiasis relates to formation of nephritic stone or renal calculi or renal crystals, [3]. [9] reported major histopathological injuries of renal tubular epithelial cell which were associated with calcium oxalate crystal formation in mouse kidney. Exposure to high level of oxalate or calcium oxalate crystals induces epithelial cellular injury resulted to apoptosis and cell death [10]. [11], experimentally proved that, Randall's plaque were responsible for development of calcium oxalate crystals leads to kidney stones in the experimental animal. Randall suggested that, accumulation of the calcium phosphate on the tip of the renal papillae provides an ideal foundation for the formation of the calcium oxalate stone [12]. Ethylene glycol found responsible for formation of kidney stone or renal calculi which has altered the cellular content and biochemical feature of nephrocytes in the experimental animals [13]. For to inhibit this activity and as a part of phytoremideation variety of medicinal plants were used in remedial purpose against urolithiasis or kidney stone without side-effect and cost effectiveness and minimum surgical operative method. [14], reported the medicinal composition of well-known antilithiatic traditional medicinal herb Tribulus terrestris ( $\mathrm{Tt}$ ) which were widely approved for its properties of diuretics antilithiatic, anti-inflammatory and anti-diabetic. It has also impact on central nervous system, cardio tonic, hepatoprotective, immunomodulatory functions. [15], reported the chemical content of another medicinal plant Amaranthus cruentus (Ac) with its chemical composition like polyphenols, tannins, flevenoids, steroids, terpenoids, saponins and bataanins responsible for its medicinal use like anti-lithiatic property.

With the available literature and information more focus is required to study phyto remideative mechanism of plant extract against urolithiasis. With this intension present study was carried out to assess effect of two different medicinal plants i.e. Tribulus terrestris and Amaranthus cruentus on ethylene glycol induced urolithiasis in Rattus norvigicus. We prepared the doses dependent mixture of AC: TT and treated against EG induced animals. Results obtained in the present investigation were interpreted with physiology of excretion in the model animal.

\section{Material and methods}

\subsection{Animal under study}

For the present investigation, female wistar rats Rattus norvigicus were used as experimental animals. Investigation was carried out with permission of authorized CPCSEA approval for animal experiment. Animals were housed individually in cages. Animals were maintained in accordance with the guidelines as per the care and use of laboratory animals. By following standard protocol, animals were breed and reared in animal house in Department of Zoology, Shivaji University, Kolhapur (1825/PO/EReBi/S/15/CPCSEA). Mean room temperature was maintained in range from $71^{\circ} \mathrm{F}$ o $72{ }^{\circ} \mathrm{F}\left(21.9{ }^{\circ} \mathrm{C}\right.$ to $22.4{ }^{\circ} \mathrm{C}$ ) with mean daily relative humidity ranged from $38 \%$ to $50 \%$ throughout study period. Experiment animals were exposed to 12-hour light/12-hour dark photoperiod. Animals were fed on regular recommended food and Reverse Osmosis (RO) treated water which was provided to animals by using calibrated bottles also suitable for dose calculations.

\subsection{Selection of the toxicant}

According to [16], variety of chemicals were preferred for induction of renal calculi in experimental animal through the exogenous administration of lithogenic material including sodium oxalate, glycolic acid, ethylene glycol (EG) and Hydroxyl-L-proline. The administration of the dose can be done by intra-peritoneal administration or by subcutaneous somatic minipump and also can be induced as miscible dose of toxicants with drinking water under oral administration method [17]. For the present study pre-determined dose of Ethylene glycol (EG) was administered orally for development of renal calculi via daily drinking water. Chemically Ethylene glycol (EG) is transparent, colorless, odorless, non-volatile, somewhat viscous liquid which has sweet taste and found precursor for production of polyester fibers [18]. Under biochemical reactions oxalic acid combines with calcium ions it forms calcium oxalate crystals deposition in kidney which result in hypocalcaemia, haematuria, crystalourea, increase creatinine and finally causes renal failure [19]. The newly formed toxic metabolites and derivatives can affect the vital systems like nervous system, cardiopulmonary and renal part [18]. The toxic metabolism of EG found complex multi-step found in vital organs like liver and kidney and endocrine glands. 


\subsection{Selection of Plants}

With the intension to assess the impact of dose for anti-calculus, anti-inflammatory and anti-lithiatic property two different plants species viz; Tribulus terrestris (L) (TT) and Amranthus cruentus (L) (AC) were used as herbal phyto remideative products [20], to inhibit impact of EG.

\subsection{Selection of organ}

With the main objective and part of investigation kidney (nephrocytes) were considered as site of stone formation, whereas uretor, urinary bladder and urethra were also assessed for their symptomatic pathological conditions during the study. To support [17], also selected and administered kidney for various lithogenic effects against nephrocytes and noticed hyperoxaluria in the different sites of kidney. Taking account of above present investigation was carried out in tissue and part of excretory system as kidney.

\subsection{Preparation of stock solution}

As the study was focused on phytoremideation against ethylene glycol induced renal calculi in the selected animal model Rattus norvigicus, three different chemicals were prepared in a bulk quantity by applying percent wise differentiations and were considered as stock solutions during the experimental procedure.

\subsubsection{Stock solution of Ethylene Glycol (EG) (0.5\% and 1\%)}

- $\quad 0.5 \%$ Ethylene Glycol (EG): $99.5 \mathrm{ml}$ distilled water + $0.5 \mathrm{ml} \mathrm{EG} \mathrm{(100 \% )}$

- $1 \%$ Ethylene Glycol (EG): $99.0 \mathrm{ml}$ distilled water + $1.0 \mathrm{ml}$ EG (100\%)

\subsubsection{Stock extracts of Tribulus terrestris (TT)}

From the healthy and selected plants, fruits were collected. Selected and completely dried same sized fruits were fine grinded up to powder form. Grinded powder was thoroughly mixed and dissolved in distilled water for overnight (24 hrs.). To the next day morning mixture was heated up to $70{ }^{\circ} \mathrm{C}$ for $15 \mathrm{~min}$. period. Through muslin cloth and filter paper, total extract was twice filtrated and collected in clean and dry calibrated glass jar. The concentrated filtrate was labeled as stock extract of Tribulus terrestris (100\% TT).

\subsubsection{Stock extracts of Amranthus cruentus (AC)}

Among healthy plant dried seed of Amranthus cruentus were collected. Same sized seeds were grinded into grinder up to fine powder. Weight powder was thoroughly mixed into distilled water and was kept for overnight. On the next day morning the mixture was heated up to $70{ }^{\circ} \mathrm{C}$. for $15 \mathrm{~min}$. period. Using muslin cloth and filter paper, total extract was twice filtered and collected in clean and dry glass jar. The concentrated filtrate was labeled as stock extract of Amranthus cruentus (100\% AC).

\subsubsection{Working solution and dose concentrations}

With the intension to study antilithiatic activity of selected medicinal plants stock extract solution of TT and AC were categorized into 3 different solutions and labeled dose concentrations as:

- 25:75 bottle: $25 \mathrm{ml} \mathrm{AC}$ extract $+75 \mathrm{ml}$ TT extract

- $50: 50$ bottle: $50 \mathrm{ml} \mathrm{AC}$ extract $+50 \mathrm{ml}$ TT extract

- $75: 25$ bottle: $75 \mathrm{ml} \mathrm{AC}$ extract $+25 \mathrm{ml}$ TT extract

\subsubsection{Experimental design}

For the present investigation adult experimental animals of average 95 - 100 days old, with body weight about 350$400 \mathrm{gm}$. were selected. The animals were grouped into six groups A to F having 6 animals in each. Group A considered as controlled which was administered with only distilled water. Group B intoxicated with $0.5 \%$ EG solution. Group C fed with $1 \%$ EG solution. Group D was treated with 25 AC: 75 TT- $20 \mathrm{ml}+20 \mathrm{ml}$ 1\% EG. Group E provided with 50 AC: 50 TT- $20 \mathrm{ml}+20 \mathrm{ml}$ 1\% EG. Group F treated with 75 AC: 25 TT- $20 \mathrm{ml}+20 \mathrm{ml}$ 1\% EG. All experimental animals with control group were treated with respective dose up to 30 days and were repeatedthrice (Figure 1). 


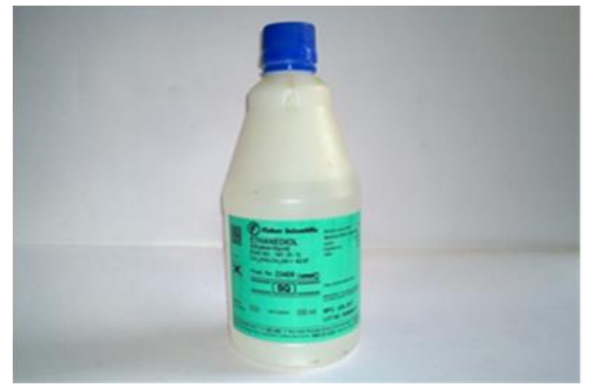

a

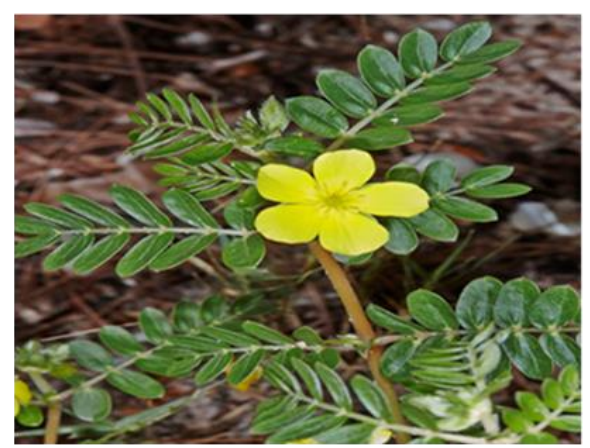

C

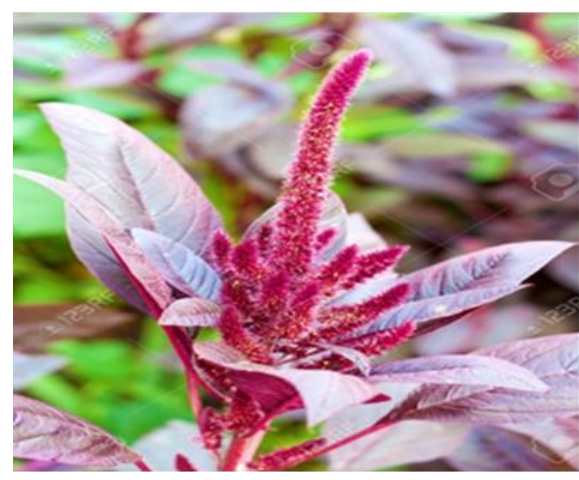

e

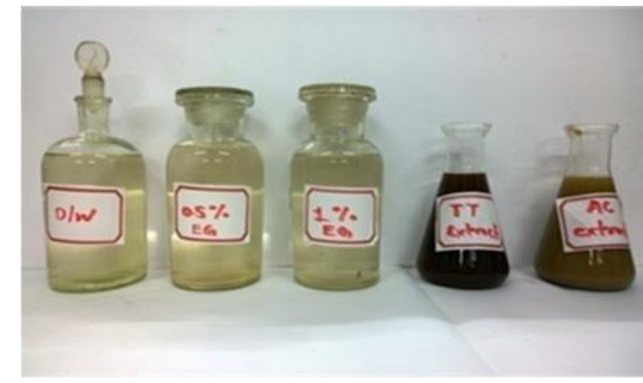

b

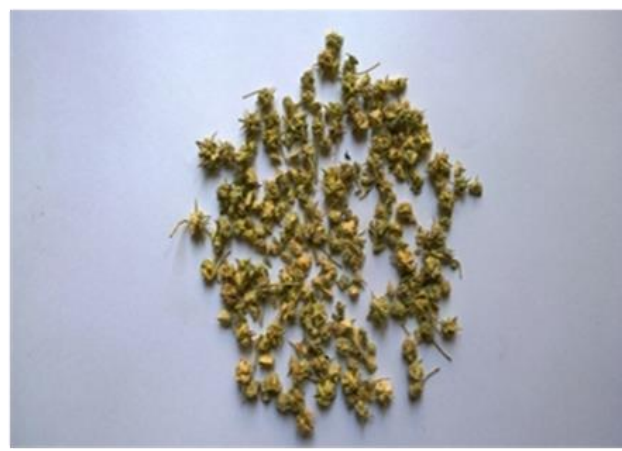

d



f

Figure 1 Plant materials used in the investigation. Figure a) and b)- For induction of calculus stalk solutions of .05\% and $1.0 \%$ EG solution, c) plant of Tribulus terrestris (TT), d) fruit and single seed of Tribulus terrestris (TT), e) plant of Amranthus cruentus (AC) and f) seeds of Amranthus cruentus (AC)

The brief idea about dose design is given as below

- Group A: Controlled animal fed with distilled water

- Group B: Experimental animal induced with 0.5 \% EG for 30 days

- Group C - Experimental animal induced $1 \%$ EG

- Group D - 25:75 (20ml) +1\% EG (20ml) for 30 days

- Group E - 50:50 (20ml) +1\% EG (20ml) for 30 days

- Group F - 75:25 (20ml) +1\% EG (20ml) for 30 days

\subsubsection{Urine analysis}

As the investigation deals with impact of EG extensive urine analysis had been conducted prior to studies. Urine samples from all the experimental groups were collected daily after $24 \mathrm{hrs}$. Interval during morning between 09.00 am. to $10.00 \mathrm{am}$. All samples were collected in dry, clean and celebrated tubes without additions of any preservatives. All the collected samples were subjected for further microscopic evaluation considering color, appearance, total volume and microscopic sedimentation. For quantitative observation of crystals during EG toxicity from both groups 1 
$\mathrm{ml}$ of the fresh urine sample was collected and centrifuged at $3000 \mathrm{rpm}$ for $10 \mathrm{~min}$. supernatant was discarded. Further type and number of the crystals were micro photographed, identified and counted under Inverted Phase Contrast microscope (LYNX).

\subsubsection{Histological techniques}

For histopathological study after completion of experimental protocol, experimental animals were sacrificed from each group. Targeted tissues of kidney were harvested and morphometrically assessed. All the tissues samples were subjected to standard micro technique procedure. From each of the experimental group histological slides were prepared and observed under microscope for both normal and pathological assessment.

\section{Results and discussion}

Urolithiasis reported as common disease depending upon lifestyle, dietary choices and other relevant factors interfering the body metabolism. Researchers also concluded that metabolic disorders like diabetes, hypertension and dislipedimia were major causative factors to increase the risk of urolithiasis. The term nephron-calcisinosis referred for attachment of crystal in the epithelial cells which lies on renal tubule. According to clinical pathology it has been noted that glyoxilate induced renal tubular cells noted nonfunctional and unable to excrete normal quantity and chemical content [21]. [22], documented antilithiatic effect of spurilunaon ethylene glycol induced male, where he reported morphological abnormalities in the nephrocytes. [23], noticed role of kidney stone inhibitors and promoters in the pathogenesis of calcium containing renal stones development. Numbers of experimental protocol were carried out for the assessment deposition and development of nephritic stone. With available literature regarding the effect of EG to induce calcification by treatment of TT and AC as a part of phytoremideation in different ratio the results obtained were as follows:

Study insights the mechanism of crystal formation induced by EG (ethylene glycol) doses against the dose dependent inhibitory process of crystal formation by two i.e. Tribulus terrestris (TT) and Amranthus cruentus (AC) plant extracts in universally accepted vertebrate model Rattus norvigicus.

\subsection{Assessment of urine sample of experimental animal}

\subsubsection{Urine Profile}

Urine of all experimental animals was collected after the 30 days of exposure period each dose cycle. Quantitatively and quality wise all samples were showed significant alterations in the process of urine formation as per dose provided to them. Among group A animals urine volume was $8.9 \mathrm{ml} /$ day. Group B animal's excreted average $5.54 \mathrm{ml}$ /day urine volume after $30^{\text {th }}$ days. Animals from group C excreted $4.1 \mathrm{ml} /$ day volume after $30^{\text {th }}$ days. Comparatively group D animal's urine volume after $30^{\text {th }}$ day was $5.5 \mathrm{ml} /$ day. Group E animal's average urine volume after $30^{\text {th }}$ day was $5.9 \mathrm{ml} /$ days. Average urine volume of group $\mathrm{F}$ animal's after $30^{\text {th }}$ day was $6.6 \mathrm{ml} /$ day. During experiment urine samples of all animal's from all groups were biochemically analyzed and were observed under phase contrast microscope. Quantitative data obtained was compared with controlled animals from group which was A fed with distilled water showing normal quantity of urine with absence of crystal's responsible to stones formation figure 2-7.

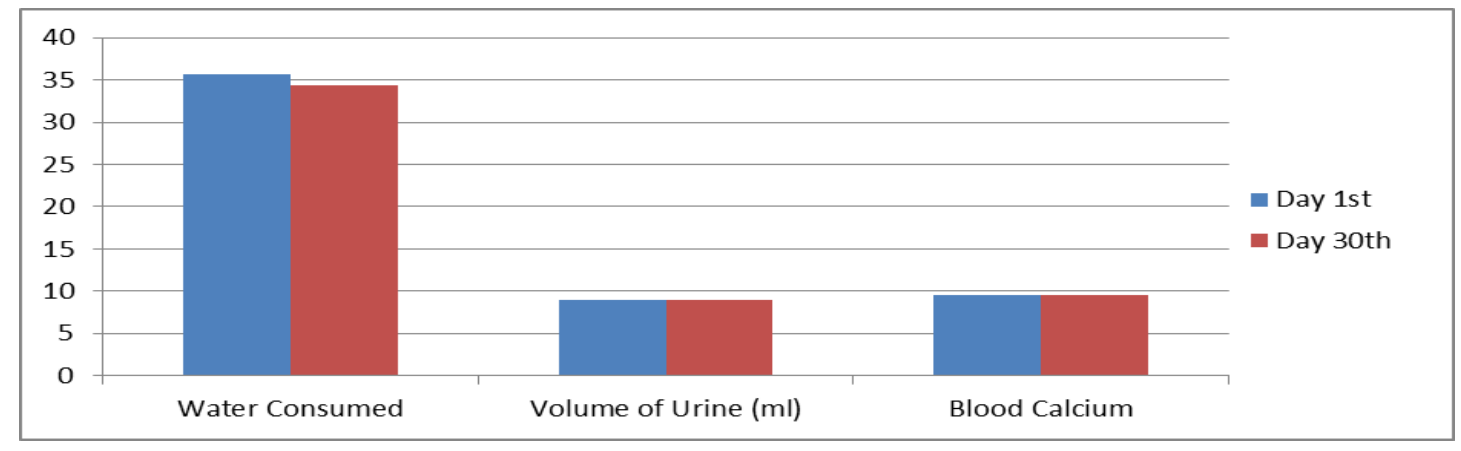

Figure 2 Water consumption and rate of urine formation in the experimental rat Rattus norvigicus 


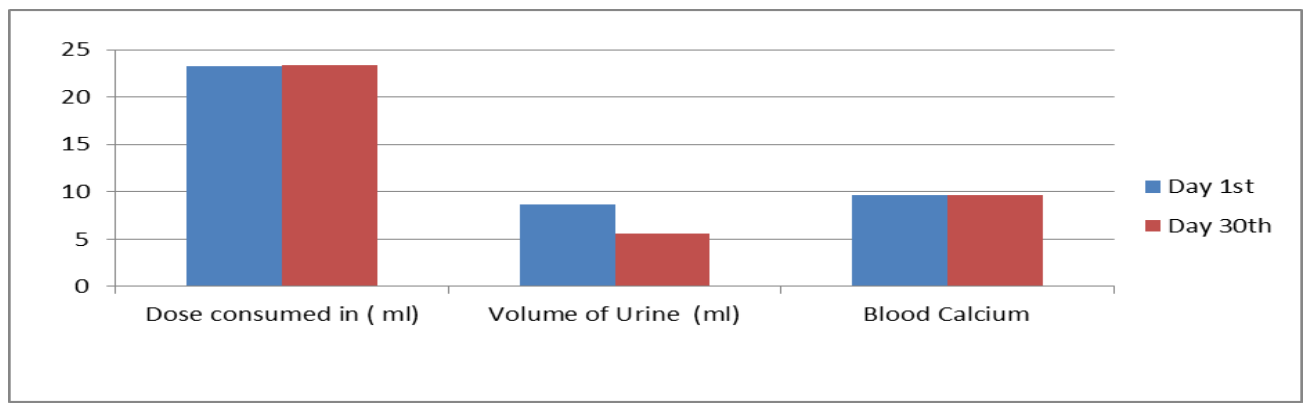

Figure $3(0.5 \% \mathrm{EG})$ dose consumption and rate of urine formation in the experimental rat Rattus norvigicus

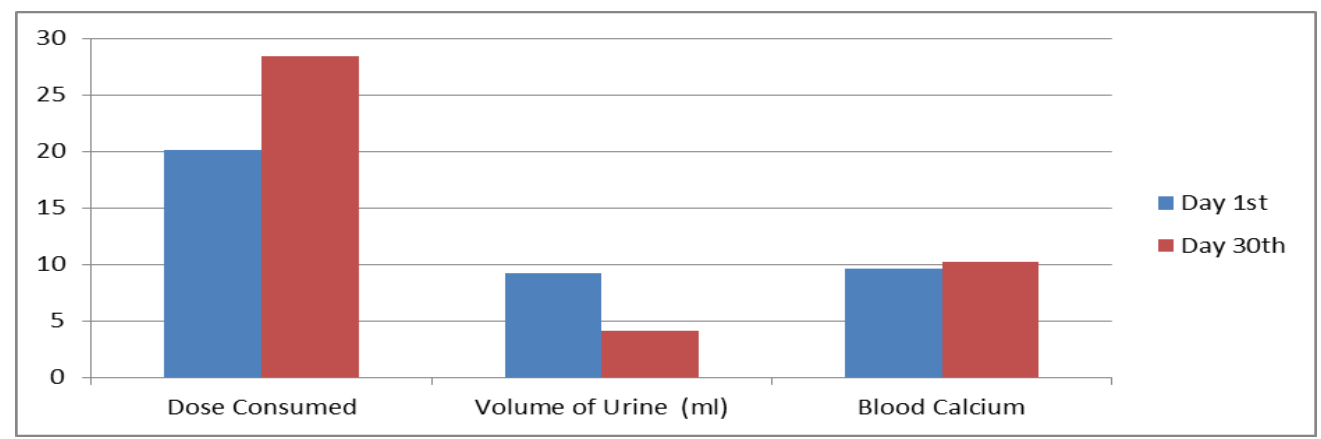

Figure 4 (1.0 \% EG) dose consumption and rate of urine formation in the experimental rat Rattus norvigicus

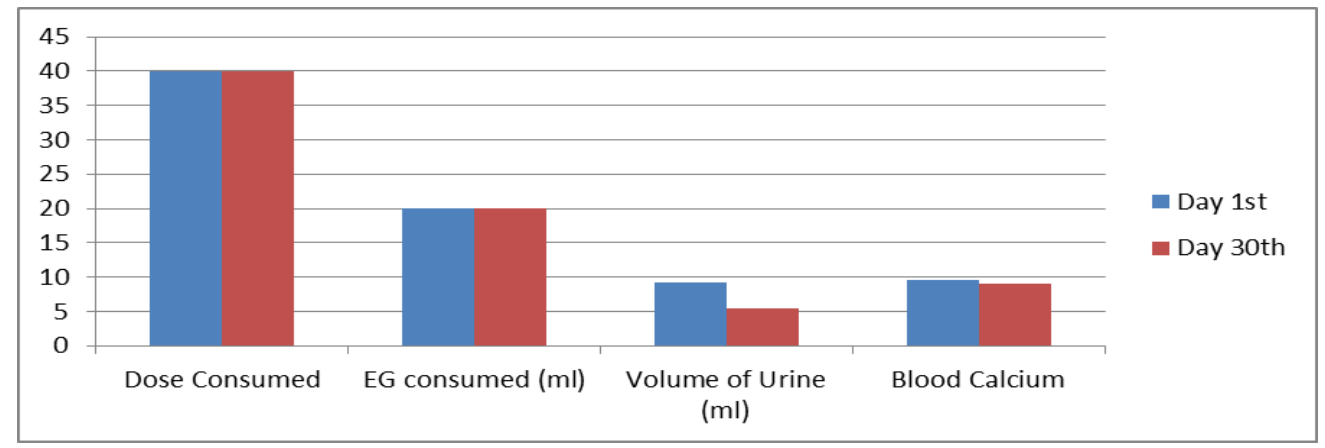

Figure 525 AC: 75 TT- $20 \mathrm{ml}+20 \mathrm{ml}$ 1\% EG dose consumption and rate of urine formation in the experimental rat Rattus norvigicus

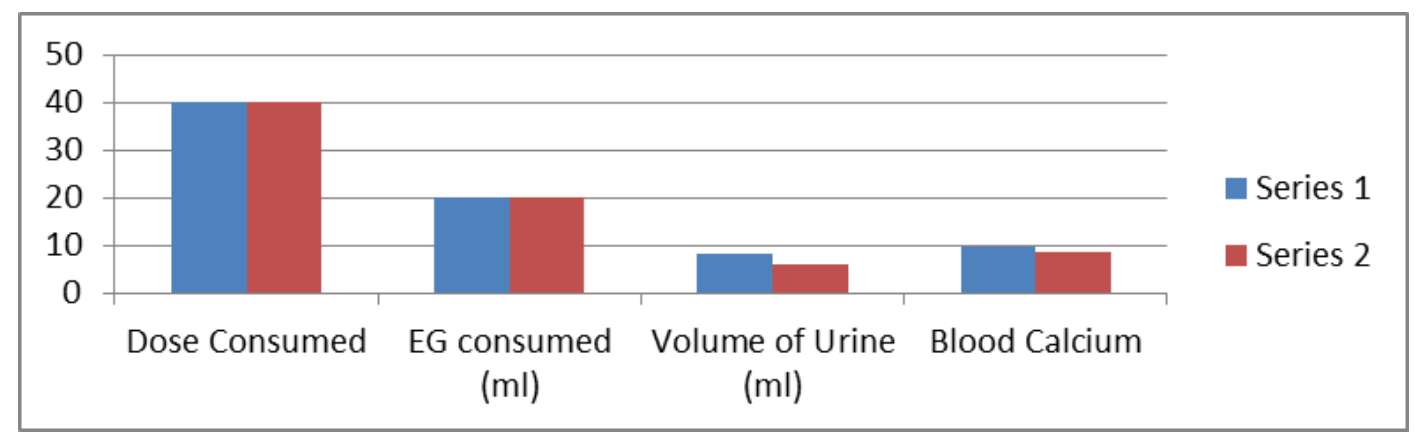

Figure 650 AC: 50 TT- $20 \mathrm{ml}+20 \mathrm{ml}$ 1\% EG dose consumption and rate of urine formation in the experimental rat Rattus norvigicus 




Figure 775 AC: 25 TT- $20 \mathrm{ml}+20 \mathrm{ml}$ 1\% EG dose consumption and rate of urine formation in the experimental rat Rattus norvigicus

Under the experimental protocol animal's from group B fed with $0.5 \%$ EG for microscopic analysis (10X) of urine sample after $30^{\text {th }}$ day of dose cycle showed moderately formed calcium oxalate crystals. Experimental animal's from group C induced with 1\% EG when in microscopically analyzed (10X) after 30th days of dose cycle showed significantly increased crystals of calcium oxalate stone. In second part as a remideative or phyto-inhibitory study

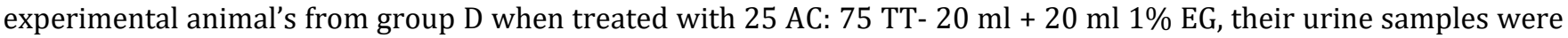
microscopically observed after $30^{\text {th }}$ days and showed some reduced percentage of calcium oxalate crystals which may inhibited the mechanism of stone formation. The experimental animal group E fed with 50 AC: 50 TT- $20 \mathrm{ml}+20 \mathrm{ml}$ 1\% EG under microscopic showed significantly depleted content of crystals on the slides. We observed that in the last experimental group $\mathrm{F}$ which was treated with dose of both plant extract in the mixture containing combination of 75 AC: 25 TT- $20 \mathrm{ml}+20 \mathrm{ml}$ 1\% EG under microscopic study urine sample showed very negligible amount of crystals of calcium oxalate. The urine sample was found clear with sufficient quantity indicating anti-urolethic impact of both plant extract (75 AC: 25 TT) against ethylene glycol effect. Figure 8.



A

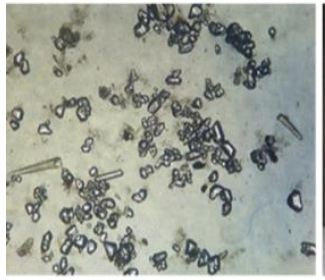

C
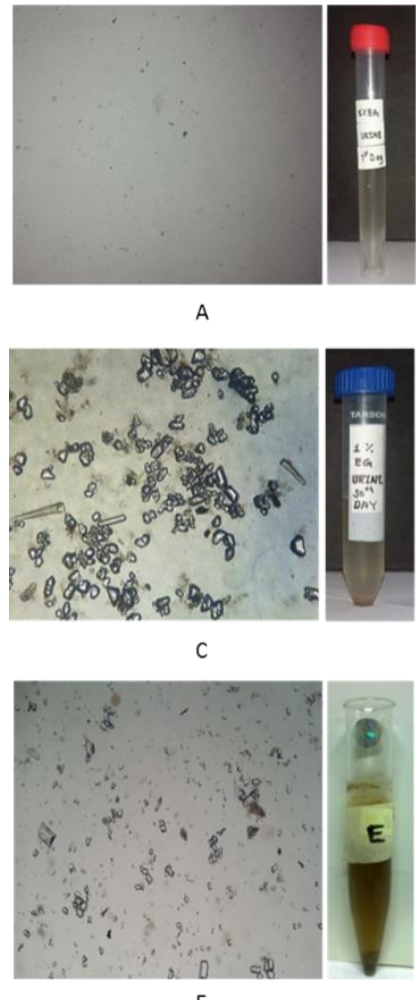

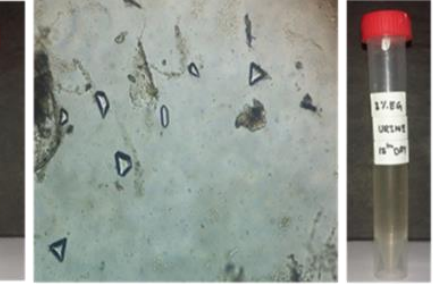

B

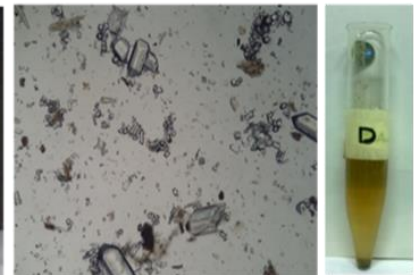

D

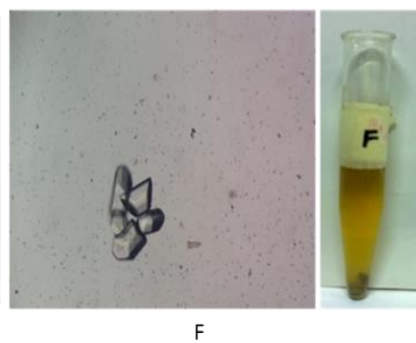

Figure 8 Photomicrographs of classified crystals of Fig A- Microscopic view of group A (control) urine sample. (10 X) Fig B - microscopic view of Group B (0.5 \% EG) urine sample (10 X); Fig C - Microscopic View of Group C (1 \% EG) urine sample. (10 X); Fig D - as phytoremideation treatment is the microscopic view of group D (25 AC: 75 TT (20 ml) + $20 \mathrm{ml}(1 \%$ EG.) urine sample. (10 X); Fig E - microscopic view of group E (50 AC: 50 TT $(20 \mathrm{ml})+20 \mathrm{ml}(1 \%$ EG.) urine sample. (10 X); Fig F - microscopic view of group F (75 AC: 25 TT (20 ml) + $20 \mathrm{ml}(1 \% \mathrm{EG}$.) urine sample $(10 \mathrm{X})$. 


\subsubsection{Histological assessments of kidney in controlled Group}

Under the microscope, normal histopathological section of kidney showed numerous uriniferous tubules. These tubule or nephron was found distinguished with cortex and medulla region. Tissue section specified vascularised central glomerulus and Bowman's capsule. In controlled animals the microscopic architecture found normal and preserved for to carry normal excretory function as per the metabolic activities (Figure9).

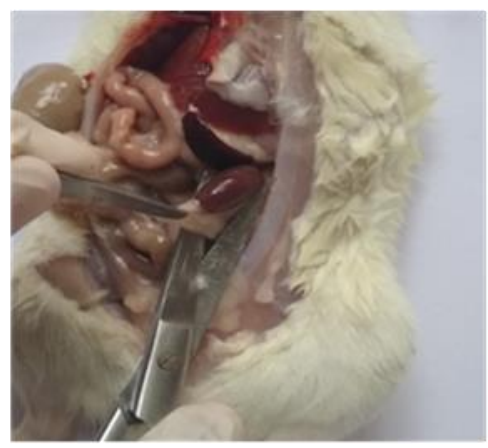

a



d

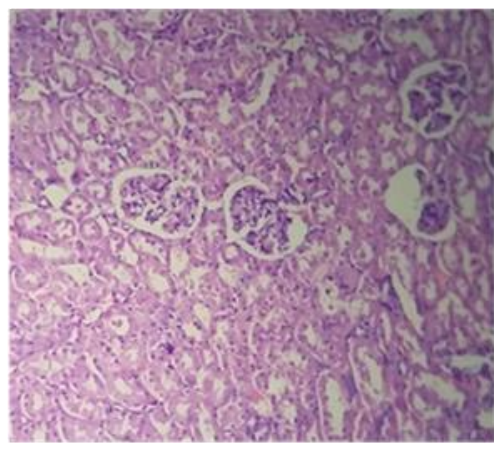

g

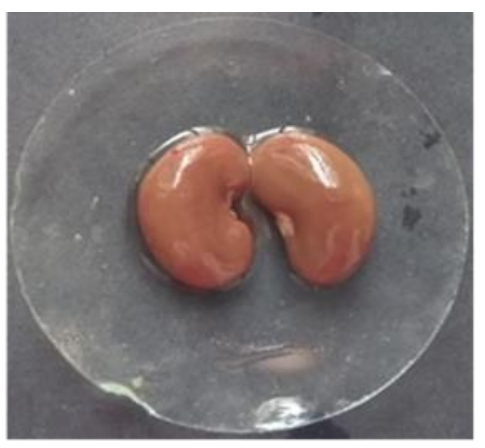

b

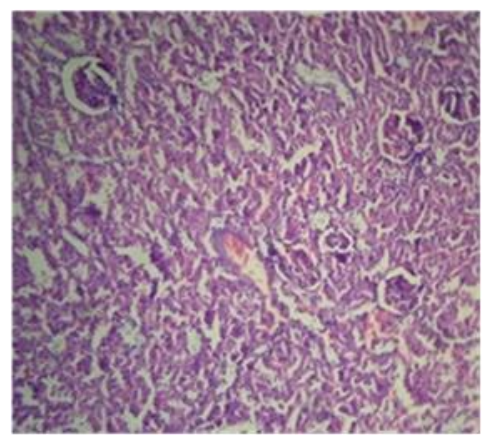

e

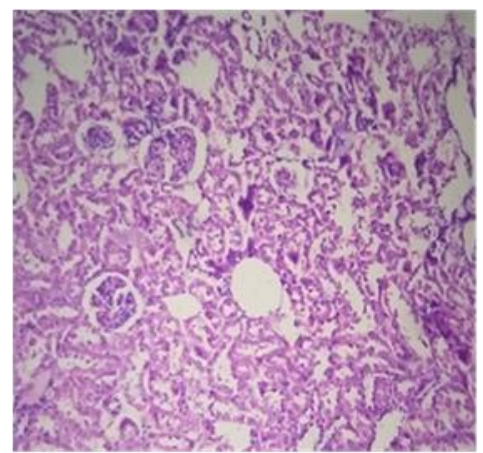

h

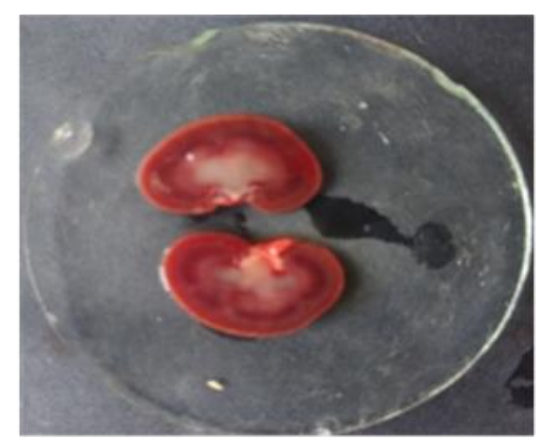

C

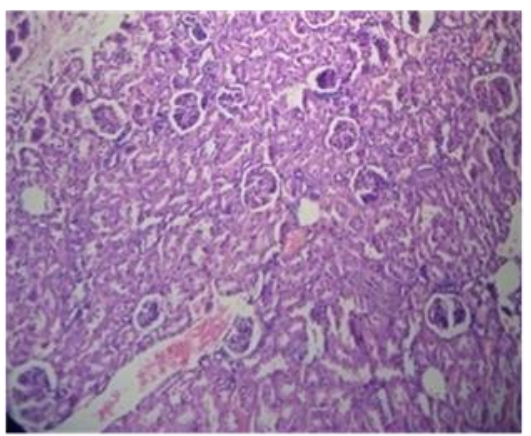

f

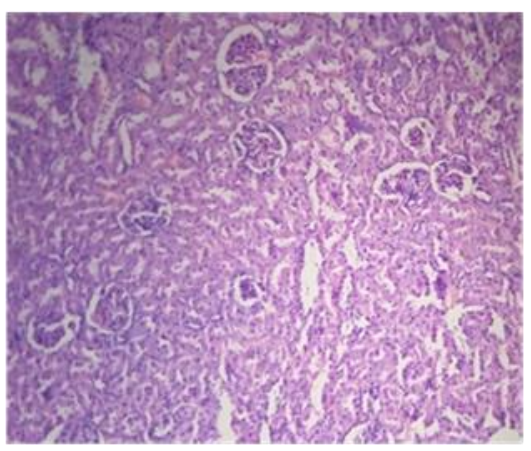

i

Figure 9 a) Anatomical and histological photomicrographs of experimental animal Rattus norvigicus showing position of kidney; b) External morphology of interested organ kidney; c) sectional view of normal kidney; d) HE stained section of controlled animals kidney with all normal histology of kidney (10 x); e) HE stained section of group B (0.5 $\%$ EG) induced kidney $(10 \mathrm{x})$; f) HE stained section of group B (1.0\% EG) induced kidney (10 x); g) HE stained nephritic section of group D( 25 AC:75 TT (20 ml) $+20 \mathrm{ml}(1 \%$ EG.) kidney (10 X); h) HE stained section of group E ( 50 AC: 50 TT $(20 \mathrm{ml})+20 \mathrm{ml}(1 \%$ EG.) kidney $(10 \mathrm{X})$; and i) HE stained nephritic cells of group F (75 AC:25 TT (20 $\mathrm{ml})+20 \mathrm{ml}(1 \% \mathrm{EG}$.$) kidney (10 \mathrm{X})$.

\subsubsection{Histopathological assessments of nephrocytes under experimental animals}

Under the experiment when animals were exposed to EG for induction of calcification after the exposure of $0.5 \%$ EG for 30 days dose cycle they showed minute structural alterations in nephrocytes of the cortex region. Under microscope medullary part showed cellular hypertrophy and swelling of the nephritic cells in kidney. Part of the section showed loss of renal tubules with development of intra-nephritic space typically found in the section. Similarly 
when animal from second group were induced with $1 \%$ dose of EG after 30 days nephritic cells were prominently deteriorated and were found separated from each other. The cortex part of kidney was more damaged. The renal tubules observed with space field with fluid having crystaled structure. Total sectional view was more disturbed as compared to controlled section.

With the main objective as phytoremideation of two plant extract against EG induced stone formation histopathological examination of sections of kidney (25 AC:75 TT- $20 \mathrm{ml}+20 \mathrm{ml} \mathrm{1 \%}$ EG) after 30 days showed moderately destructed cortex region of the kidney. Sectional images were noticed with minute loss of renal tubules i.e. the content AC and TT (25: 75) has minimized toxic impact of ethylene glycol. In the next group of animals which has provided (50 AC: 50 TT- $20 \mathrm{ml}+20 \mathrm{ml}$ 1\% EG) dose after 30 days showed mild cellular damage. The cortex and medullary region was slightly hypertrophic and with minute fluid filled space in between the cells. In the last group treated with (75 AC:25 TT - $20 \mathrm{ml}+20 \mathrm{ml} \mathrm{1 \%} \mathrm{EG)} \mathrm{dose} \mathrm{after} 30$ days sectional view was comparatively remained undisturbed and has preserved normal cellular content with about 80 to $90 \%$ similar section as that of normal animals. An experimental animal in last group were found normal and has excreted normal volume of the urine with very negligible amount of calcium crystals in it. Our results coincides with [24] were they showed that species Amranthus viridis was used as anti-inflammatory agent, vermifuse, diuretics and for the treatment in kidney stones a anti-urolithiatic agent. [25], also reported phytochemical and antimicrobial activity of Tribulus terrestris in experimental animal $R$. norvigicus to reduce the percentage of calcification. [26], reported the phyto- remedial impact of Amranthus cruentus leading to significantly reduction of calcium oxalate crystals which has direct impact on regulation of excretory system and urine formation.

Traditional herbal medicinal plants found with lesser side effects and economic in nature with herbal therapy which proved its diuretic activity, crystallization inhibitor activity, lithotrophic activity, anti-inflammatory activity and has increased renal functions [27]. TT extract were used for is high potential activity like diuretics, antiurolithic, immunomodulatory, anti-diabetic, absorption enhancing, hypolipidemic, cardio tonic, central nervous system, hepatoprotective, anti-inflammatory, analgesic, antispasmodic, anticancer, antibacterial [14]. As well as TT showed activities like Cytotoxic effects, antispasmodic activity, cardio protective effects, effect on hypertension, wound healing activity [28].

Related to remediation point of view variety of species of Amaranth has been used for recovery in the pathology like diuretic, cold and cough, urinary and throat trouble, gastric problems [29]. [30], reported number of biochemical and nutritional strategies and doses of food to prevent urolithiasis in animals. In calcium oxalate crystals calcium oxalate monohydrate crystals (COM) is oxalate dependent whereas calcium oxalate dehydrate crystals (COD) was calcium dependent [17]. Researchers documented that glycosaminoglycan's (GAGs), lipid, carbohydrates and protein; these molecules play an important role in a formation and also inhibiting process of kidney stone formation [10]. In case atherosclerotic condition vasculature in renal system leads to calcification and developed into larger stone as per amount of supersaturated urine [31]. [32], documented various aspects of drug therapies to overcome the problem of nephritic calculation and urolithiasis. Oxalate found to be main precursor for formation of the kidney stone so dietary component including oxalate rich like cucumber, including green peppers, beetroot, spinach, soya been, chocolate, sweet potato should consume in balance manner.[33], also documented dietary restrictions for the prevention of calcification in the nephritic cells. Water therapy / consumption reported as best remedy for suppress the risk of stone formation [34]. [35], provided information regarding preventive measures of recurrent mechanism of stoneformation and also gave some insight for compliance to overcome the pathological symptoms of urolithiasis.

\section{Conclusion}

Overall in the present investigation we found that in both $0.5 \%$ and $1.0 \%$ ethylene glycol induced animals they showed significantly increased calcium oxalate crystal in their kidney with pathologically disturbed nephritic cells. Percent wise concentrated oxalate crystals were more responsible for the stone formation. But under phyto remideative effect extract of (75 AC: $25 \mathrm{TT}-20 \mathrm{ml}+20 \mathrm{ml} \mathrm{1 \%} \mathrm{EG)} \mathrm{has} \mathrm{prominently} \mathrm{worked} \mathrm{against} \mathrm{the} \mathrm{mechanism} \mathrm{of}$ calcium oxalate formation to restrict the calcification. In the experiment we found that comparatively in the mixture of AC: TT (75: 25) ratios found more remideative for to inhibit or reduce the calcium crystal formation in the kidney. The result of the investigation indicates that among the mixture AC: TT (75: 25) 75\% concentration of AC has more inhibitory activity to prevent the calcification and stone formation which can be successfully implemented for total recovery and normal function of kidney. 


\section{Compliance with ethical standards}

\section{Acknowledgments}

We are thankful to the Head of Department of Zoology, Shivaji University, Kolhapur for providing facility to carry out present work.

\section{Disclosure of conflict of interest}

The authors declare that they have no conflicts of interest.

\section{Statement of ethical approval:}

Investigation was carried out with permission of authorized CPCSEA approval for animal experiment. Department of Zoology, Shivaji University, Kolhapur (1825/PO/EReBi/S/15/CPCSEA).

\section{References}

[1] Shriganesh RB, SachinSoni, Sonali S and Ashish B. (2012). Medical management of renal stone. Indian Journal of Endocrinology and metabolism, 16(2).

[2] Katuvaut P, Amnuay Wk and Jukkaphun N. (2010). Application of small caltrops (TT) to inhibit calcium oxalate monohydrate crystallization. Science Asia, 36, 165-168.

[3] Atul S and Papiya B. (2017). A review on Epidemiology and Etiology of Renal stone. American Journal of Discovery and Development, 7(2), 54-62.

[4] Keoghane S, Walmsley B and Hodgson D. (2009). The natural history of untreated renal tract calculi. BJU International, 105 (12), 1627-1629.

[5] P. Kambhoj, M Aggarwal, S. Puri and S. K. Singla. (2011). Effect of aqueous extract of Tribulus terrestris on oxalate induced oxidative stress in rats. Indian J Nephrol, 21(3), 154-159.

[6] Tilahun A and Beyene Petros. (2018). Kidney stone disease: An update on current concept. Advances in Urology, Vol. 2018/3068365.

[7] Xi Q, Ouyang J, Pu J, Hou J and Wang S. (2015). High concentration of calcium stimulates calcium oxalate crystal attachment to rat tubular epithelial NRK cells through osteopontin. Urology, 86(4), 844.e1-844e5.

[8] Anja Pfau and Felix Knauf. (2016). Update on Nephrolithiasis: Core Curriculum 2016, Am J kidney Dis, 68, $973-$ 985.

[9] Hirose M, Yasui T, Okada A, Hamamoto S, Shimizu H, Itoh Y, Tozawa K and Kohri K. (2010). Renal tubular epithelial cell injury and oxidative stress induce calcium oxalate crystal formation in mouse kidney. International journal of urology, 17(1), 83-92.

[10] Tilahun A and Deyene P. (2018). Kidney Stone desease: An update on current concepts, Hindivi, Advances in urology, Vol. 2018, 1-12.

[11] Davidov MI and Igoshev AM. (2015). The effect of the herbal preparation Canefron ${ }^{\circledR} \mathrm{H}$ on the results of distance shock-wave lithotripsy. Health Man, 4(55), 96-100.

[12] Anja Pfau and Felix Knauf. (2016). Update on Nephrolithiasis: Core Curriculum 2016. Am J kidney Dis, Vol 68, 973-985.

[13] Jiri P and zdenek H. (2010). Ethylene glyucol, Hazardous substance in the housesold. ACTA MEDICS, 53(1), 1923.

[14] Suresh RY, Sathyanarayana D and Kannan K. (2016). A recent phytochemical Review- fruits of Tribulus terrestris. J. Pharm. Sci. and Res., 8(3), 132- 140.

[15] Fernand WN, Adama H, Jeanne FM and Odile GN. (2012). Phyto chemical compostion, antioxidant and xanthine oxidase inhibitory activity of Amranthus cruentus L. and Amaranthus hybridua L. extract, Phar. Journals, 613628. 
[16] Cakıroglu B, Eyyupo glu E, Hazar AI, Uyanik BS and Nuho glu B. (2016). Metabolic assessment of recurrent and Irst renal calcium oxalate stone formers. Archivio Italiano diUrologia e Andrologia, 88,101-105.

[17] Heloise B and Jean Ph. (2016). Experimental models of renal calcium stones in rodents. World Journal of Nephrology, 5, 189-194.

[18] HairongYue, yujun Z, Xinbin M and Jinlong G. (2011). Ethylene glycol: Properties, synthesis and applications. The royal society of Chemistry, 41, 4218-4244.

[19] Jiri P and zdenek H. (2010). Ethylene glyucol, Hazardous substance in the houses old. ACTA MEDICS, 53(1), 1923.

[20] Suresh RY, Sathyanarayana D and Kannan K. (2016). A recent phytochemical Review- fruits of Tribulus terrestris. J. Pharm. Sci. And Res., 8(3), 132-140.

[21] Hirose M, Yasui T, Okada A, Hamamoto S, Shimizu H, Itoh Y, Tozawa K and Kohri K. (2010). Renal tubular epithelial cell injury and oxidative stress induce calcium oxalate crystal formation in mouse kidney. International journal of urology, 17(1), 83-92.

[22] JW Yuen, MDI Gohel, NW Poon, DKY Shum, PC Tam and DWT Au. (2010). Initial and subsequent in Eammatory events during calcium oxalate lithiasis. Clinica Chimica Acta, 411, 1018-1026.

[23] Basavaraj DR, Biyani CS, Browning AJ and Cartledge JJ. (2007). The role of urinary kidney stone inhibitors and promoters in the pathogenesis of calcium containing renal stones. EAU-EBU update series, 5(3), 126-136.

[24] Asha S and Thirunanavukkarasu P. (2013). Antiurolithiatic activity of amaranthus viridis on ethylene glycol induced male rat. Inventi Rapid pharmacognosy, 13(4).

[25] Hashim S, Bakht T, Marwat KB and Jan A. (2014). Medicinal properties, phytochemistry and pharmacology of Tribulus terrestris L. (Zygophyllaceae). Pakistan Journal of Botany, 46(1), 399-404.

[26] MA kram, HM Asif and Khalil A. (2011). Tribulus terrestris Linn: A review article. Journal of Medicinal Plants Res, 5(16), 3601-3605.

[27] Ajay KS, Surat S, Ashish G and Shweta G. (2017). A review on anti urolithiatic activity of herbal folk plant. Asian Journal of Biomaterial research, 3(2), 1-11.

[28] Varma P, Galib P and PK Prajapati. (2013). Tribulus terrestris linn: A phytopharma cologialbrevie. Journal of Ayurveda and Holistic Medicine, Vol. 1/issue 3.

[29] Anurastogi and Sudhir S. (2013). Amranth: a new millennium crop of nutracecutical value. Food science and Nutrition, 53, 109-125.

[30] Samal L, Pattanaik AK, Mishra C, Maharana BR, Sarangi LN and Baithalu RK. (2011). Nutritional stretegies to prevent urolithiasis in animals. Veterinary World, 4(3), 142.

[31] Shweta B, Archaana NS and Tewari D. (2017). Urolithiasis: An update on Diagnostic modalities and treatment protocols. Indian J Pharmaceutical Sci., 79(2), 164-174.

[32] Alyaev Y and Rudenko V. (2016). Current aspects of drug treatment of patients with urolithiasis. Efective Pharmacotherapy. Urology and Nephrology, 5 (41), 10-16.

[33] Shriganesh RB, Uthaya J and Annaddurai G. (2018). Review on Urolithiasis pathophysiology and aesculapian discussion. IOSR Jor, of Pharmacy, 8, 30-42.

[34] Butterweck V and Khan SR. (2009). Herbal medicines in the management of urolithiasis: alternative or complementary? Planta medica, 75(10), 1095-1103.

[35] Kok DJ. (2015). The preventive treatment of recurrent stone-formation: how can we improve compliance in the treatment of patients with recurrent stone disease? Urolithiasis, 44 (1), 83-90.

\section{How to cite this article}

Sutar VS and Kamble NA. (2019), Phytoremideation of ethylene glycol induced renal calculi in the vertebrate model Rattus norvigicus. GSC Biological and Pharmaceutical Sciences, 8(1), 01-11. 